\title{
0 Uso de Cloro na Desinfecção de Águas, a Formação de Trihalometanos e os Riscos Potenciais à Saúde Pública
}

\author{
Chlorine Use in Water Disinfection, Trihalomethane Formation, and \\ Potential Risks to Public Health
}

\begin{abstract}
Sheila T. Meyer
MEYER, S. T. Chlorine Use in Water Disinfection, Trihalomethane Formation, and Potential Risks to Public Health. Cad. Saúde Públ., Rio de Janeiro, 10 (1): 99-110, Jan/Mar, 1994.

Before the development of the germ theory — relating microorganisms with disease transmission (1880) - people believed that diseases were transmitted by odours. Water and sewage disinfection emerged as a method for elimination of odours. There are many disinfecting agents, but chlorine is the main product used to disinfect water. Organic compounds present in water that is chlorinated can result in the formation of trihalomethanes. The latter are basically one atom of carbon, one of hydrogen, and three of a halogen (chlorine, bromine, or iodine). These are considered carcinogenic compounds and their presence in drinking water should therefore be avoided. Epidemiological research has shown an association between trihalomethane concentration and cancer morbidity and mortality for some types of carcinoma. Nevertheless, there may be more risk than benefit involved in replacing chlorine with other disinfecting agents, since the incidence of water-borne diseases only dropped after water chlorination became a routine procedure.
\end{abstract}

Key words: Water Treatment; Chlorine; Trihalomethanes

\section{INTRODUÇÃO}

A desinfecção da água tem sido praticada por milênios, embora os princípios envolvidos no processo não fossem conhecidos. Existem indícios de que o uso de água fervida já era recomendado em 500 a.C., mas alguns historiadores julgam que esta prática era adotada desde o começo da civilização (Iabusch, 1971). Até que a teoria dos microorganismos fosse estabelecia (Louis Pasteur, 1880), havia a crença de que as doenças eram transmitidas através de odores. A desinfecção da água e dos esgotos surgiu como uma tentativa de se controlar a propagação das doenças através dos odores.

\footnotetext{
${ }^{1}$ Secretaria do Meio ambiente Ciência e Tecnologia do Distrito Federal. Instituto de Ecologia e Meio Ambiente. SRTVS Quadra 701, Centro Empresarial Assis Chateaubriand, $6^{\circ}$ andar, Brasília, DF, 70340-906, Brasil.
}

\section{DESINFECÇÃO}

Os processos de desinfecção têm como objetivo a destruição ou inativação de organismos patogênicos, capazes de produzir doenças, ou de outros organismos indesejáveis. Esses organismos podem sobreviver na água por várias semanas, em temperaturas próximas a $21^{\circ} \mathrm{C}$ e, em alguns casos, por vários meses, em baixas temperaturas (Cubillos, 1981). A sobrevivência desses organismos na água depende, não só da temperatura, mas também de outros fatores ecológicos, fisiológicos e morfológicos, tais como: $\mathrm{pH}$, turbidez, oxigênio, nutrientes, competição com outros organismos, resistência a substâncias tóxicas, habilidade na formação de esporos (Rossin, 1987). A desinfecção não implica, necessariamente, a destruição completa de todas as formas vivas (esterilização), embora muitas vezes o processo de desinfecção seja levado até o ponto de esterilização. 
Segundo Laubush (1971), os fatores que influem na desinfecção e, portanto, no tipo de tratamento a ser empregado, podem ser resumidos em:

- espécie e concentração do organismo a ser destruído;

- espécie e concentração do desinfetante;

- tempo de contato;

- características químicas e físicas da água;

- grau de dispersão do desinfetante na água.

A resistência de algumas espécies de microorganismos a desinfetantes específicos varia consideravelmente. Bactérias não-esporuladas são menos resistentes que as formadoras de esporos; formas encistadas e vírus podem ser bastante resistentes (Rossin, 1987).

A concentração de microorganismos é um outro fator importante, já que uma densidade elevada significa uma maior demanda de desinfetante. A aglomeração de organismos pode criar uma barreira para a penetração do desinfetante.

A morte de organismos pela ação de um desinfetante, fixando-se os outros fatores, é proporcional à concentração do desinfetante e ao tempo de reação. Deste modo, pode-se utilizar altas concentrações e pouco tempo, ou baixas concentrações e um tempo elevado.

As características da água a ser tratada têm influência marcante no processo de desinfecção. Quando o agente desinfetante é um oxidante, a presença de material orgânico e outros compostos oxidáveis irá consumir parte da quantidade de desinfetante necessária para destruir os organismos (Degrémont, 1979). Alguns desinfetantes, quando em contato coma água, sofrem hidrólise e se dissociam, formando compostos com ação germicida diferente daquela da substância inicial. A temperatura do sistema influencia o caráter químico da água, já que alguns compostos podem se apresentar sob formas diferentes, conforme a temperatura do meio. Em geral, temperaturas elevadas favorecem a ação desinfetante.

Os desinfetantes químicos necessitam ser uniformemente dispersos na água, para garantir uma concentração uniforme; portanto, a agitação favorece a desinfecção.

A ação dos desinfetantes na destruição ou inativação dos microorganismos não é instantâ- nea. Em geral, o processo se desenvolve de maneira gradativa, ocorrendo etapas físicas, químicas e bioquímicas.

A desinfecção da água pode ser obtida pela utilização de diversos meios. Durante os processos numa estação de tratamento de água (ETA) convencional, as etapas de sedimentação, coagulação e filtração removem parte dos organismos patogênicos e outros presentes na água. Os processos específicos de desinfecção podem ser classificados como (Laubusch, 1971):

- tratamento físico - aplicação de calor; irradiação, luz ultravioleta e outros agentes físicos;

- íons metálicos - cobre e prata;

- compostos alcalinos;

- compostos tensoativos - sais de amônia quaternários;

- oxidantes - halogênios, ozônio e outros compostos orgânicos e inorgânicos.

As características necessárias para um bom desinfetante podem ser resumidas em (Fair et al. apud Rossin, 1987):

- capacidade de destruir, em um tempo razoável, os organismos patogênicos a serem eliminados, na quantidade em que se apresentam e nas condições encontradas na água;

- o desinfetante não deve ser tóxico para o homem e para os animais domésticos e, nas dosagens usuais, não deve causar à água cheiro e gosto que prejudiquem o seu consumo;

- seu custo de utilização deve ser razoável, além de apresentar facilidade e segurança no transporte, armazenamento, manuseio e aplicação;

- a concentração na água tratada deve ser fácil e rapidamente determinável;

- deve produzir concentração residuais resistentes na água, de maneira a constituir uma barreira sanitária contra eventual recontaminação antes do uso.

\section{EVOLUÇÃO DOS PROCESSOS DE CLORAÇÃO DA ÁGUA}

O uso de cloro na desinfecção da água foi iniciado com a aplicação do hipoclorito de 
sódio $(\mathrm{NaOCl})$, obtido pela decomposição eletrolítica do sal.

Inicialmente, o cloro era empregado na desinfecção de águas somente em casos de epidemias. A partir de 1902, a cloração foi adotada de maneira contínua na Bélgica. Em 1909, passou a ser utilizado o cloro guardado em cilindros revestidos com chumbo.

De acordo com Rossin (1987), os processos de cloração evoluíram com o tempo, podendo esta evolução ser caracterizada em diferentes décadas:

- 1908 a 1918 - início da cloração das águas; aplicação de uma pequena quantidade de cloro;

- 1918 a 1928 - acentuada expansão no uso de cloro líquido;

- 1928 a 1938 - uso de cloraminas, adição conjunta de amônia e cloro, de modo a se obter um teor residual de cloraminas. Ainda não eram empregados testes específicos para se determinar os residuais de cloro;

- 1948 a 1958 - refinamento da cloração; determinação das formas de cloro combinado e livre; e cloração baseada em controles bacteriológicos.

\section{PRINCÍPIOS DA CLORAÇÃO DA ÁGUA}

O uso de cloro no tratamento da água pode ter como objetivos a desinfecção (destruição dos microorganismos patogênicos), a oxidação (alteração das características da água pela oxidação dos compostos nela existentes) ou ambas as ações ao mesmo tempo. A desinfecção é o objetivo principal e mais comum da cloração, o que acarreta, muitas vezes, o uso das palavras "desinfecção" e "cloração" como sinônimos (Bazzoli, 1993).

O cloro e seus compostos são fortes agentes oxidantes. Em geral, a reatividade do cloro diminui com o aumento do $\mathrm{pH}$, e sua velocidade de reação aumenta com a elevação da temperatura.

As reações do cloro com compostos inorgânicos redutores, como sulfitos, sulfetos, íon ferroso e nitrito, são geralmente muito rápidas. Alguns compostos orgânicos dissolvidos também reagem rapidamente com o cloro, mas, em geral, são necessárias algumas horas para que a maioria das reações do cloro com compostos orgânicos se complete.

Quando o cloro é adicionado a uma água quimicamente pura ocorre a seguinte reação (Degrémont, 1979):

$$
\mathrm{Cl}_{2}+\mathrm{H}_{2} \mathrm{O} \rightleftharpoons \mathrm{HOCl}+\mathrm{H}^{+}+\mathrm{Cl}^{-}
$$

Na temperatura ambiente, o tempo de reação é de décimos de segundo (Van Bremem, 1984). Em solução diluída e pH acima de 4, o equilíbrio da reação é deslocado para a direita, ficando pouco $\mathrm{Cl}_{2}$ em solução. Em valores de $\mathrm{pH}$ mais baixos, a reação predominante é no sentido de formação do cloro.

$\mathrm{O}$ ácido hipocloroso $(\mathrm{HOCl})$, formado pela adição de cloro à água, se dissocia rapidamente (Degrémont, 1979):

$$
\mathrm{HOCl} \rightleftharpoons \mathrm{H}^{+}+\mathrm{OCl}^{-}
$$

A ação desinfetante e oxidante do cloro é controlada pelo ácido hipocloroso, um ácido fraco. Em solução aquosa e valores de $\mathrm{pH}$ inferiores a 6, a dissociação do ácido hipocloroso é fraca, sendo predominante a forma nãodissociada $(\mathrm{HOCl})$.

Em soluções de $\mathrm{pH}$ menor que 2, a forma predominante é o $\mathrm{Cl}_{2}$; para valores de $\mathrm{pH}$ próximo a 5, a predominância é do $\mathrm{HOCl}$, tendo o $\mathrm{Cl}_{2}$ desaparecido. A forma $\mathrm{ClO}$ predomina em pH 10 (Bazzoli, 1993; Degrémont, 1979).

As águas de abastecimento, em geral, apresentam valores de $\mathrm{pH}$ entre 5 e 10 , quando as formas presentes são o ácido hipocloroso ( $\mathrm{HOCl})$ e o íon hipoclorito $(\mathrm{OCl})$.

O cloro existente na água sob as formas de ácido hipocloroso e de íon hipoclorito é definido como cloro residual livre (Opas, 1987; Rossin, 1987).

O cloro também pode ser aplicado sob as formas de hipoclorito de cálcio e hipoclorito de sódio, os quais, em contato com a água, se ionizam conforme as reações:

$$
\begin{gathered}
\mathrm{Ca}\left(\mathrm{OCl}_{2}+\mathrm{H}_{2} \mathrm{O} \rightleftharpoons \mathrm{Ca}^{+2}+2 \mathrm{OCl}^{-}+\mathrm{H}_{2} \mathrm{O}\right. \\
\mathrm{NaOCl}+\mathrm{H}_{2} \mathrm{O} \rightleftharpoons \mathrm{Na}^{+}+\mathrm{OCl}^{-}+\mathrm{H}_{2} \mathrm{O}
\end{gathered}
$$


O íon hipoclorito também estabelece um equilíbrio com os íons de hidrogênio, dependendo do pH, ou seja, da concentração de íons de hidrogênio na água. Uma parte do cloro disponível reage com água para formar ácido hipocloroso, íons hipoclorito e ácido clorídrico. O ácido clorídrico formado combina-se com a alcalinidade natural da água ou com a alcalinidade introduzida para fins de tratamento, reduzindo-as e alterando, desta forma, o pH, o qual, por sua vez, influi no grau de dissociação do ácido hipocloroso.

Quando existem, na água, amônia e compostos amoniacais, com a adição de cloro são formados compostos clorados ativos, denominados cloraminas.

O cloro presente sob a forma de cloraminas é denominado cloro residual combinado (Opas, 1987; Rossin, 1987).

O cloro sob a forma de ácido hipocloroso combina-se com a amônia presente na água, formando monocloramina $\left(\mathrm{NH}_{2} \mathrm{Cl}\right)$, dicloramina $\left(\mathrm{NHCl}_{2}\right)$ e tricloramina ou tricloreto de nitrogê$\operatorname{nio}\left(\mathrm{NCl}_{3}\right)$.

$$
\begin{gathered}
\mathrm{NH}_{4}^{+}+\mathrm{HOCl} \rightleftharpoons \mathrm{NH}_{2} \mathrm{Cl}+\mathrm{H}_{2} \mathrm{O}+\mathrm{H}^{+} \\
\mathrm{NH}_{2} \mathrm{Cl}+\mathrm{HOCl} \rightleftharpoons \mathrm{NHCl}_{2}+\mathrm{H}_{2} \mathrm{O}
\end{gathered}
$$

$$
\mathrm{NHCl}_{2}+\mathrm{HOCl} \rightleftharpoons \mathrm{NCl}_{3}+\mathrm{H}_{2} \mathrm{O}
$$

$A$ adição de cloro em águas que contenham nitrogênio amoniacal poderá produzir uma série de reações, que dependerão da relação entre o cloro dosado e o nitrogênio amoniacal presente, do $\mathrm{pH}$, da temperatura e do tempo de reação (Rossin, 1987; Van Bremem, 1984). O cloro residual (cloro residual combinado) inicialmente aumenta com o aumento do cloro aplicado, passando por um máximo, e, em seguida, diminui até um mínimo; a partir deste mínimo, o cloro residual, agora sob a forma de cloro residual livre, aumenta proporcionalmente com a quantidade de cloro aplicada. O ponto de inflexão encontrado é chamado de breakpoint (cloração ao breakpoint). Com o início da cloração, o nitrogênio amoniacal consome o cloro na formação de cloraminas. O ponto máximo é atingido quando toda a amônia disponível se combinou com o cloro para a formação de cloraminas. Como são compostos quimicamente instáveis, quando a curva atinge o máximo, com a continuação da adição de cloro à água as cloraminas são oxidadas e destruídas, formando produtos inertes, como $\mathrm{N}_{2}$ e $\mathrm{HCl}$. O ponto mínimo de inflexão é atingido depois da destruição das cloraminas.

A continuação da adição de cloro significará um aumento do cloro residual livre, já que toda a demanda de cloro pela água foi satisfeita (Opas, 1987).

A cloração ao breakpoint pode ser aproveitada de forma a garantir um teor de cloro residual num sistema de distribuição de água (Bazzoli, 1993). A água clorada sofre adição de compostos de amônia, formando as cloraminas. Durante a distribuição da água tratada, as cloraminas funcionarão como uma fonte de cloro frente a qualquer substância oxidável que surgir na rede (recontaminação). $\mathrm{O}$ pH da solução influencia as quantidades relativas das cloraminas presentes.

As dicloraminas têm maior efeito bactericida do que as monocloraminas. As tricloraminas não apresentam efeito desinfetante.

Essas reações podem ocorrer simultaneamente, e o aumento de acidez e da relação cloro/nitrogênio favorece a formação dos derivados mais clorados.

As reações são mais rápidas em valores de pH mais baixos, onde é elevada a concentração de ácido hipocloroso não-dissociado (Van Bremem,1984).

A presença de ferro e manganês na água também afeta a cloração. Caso o pH seja elevado o bastante para que haja a formação de hidróxidos e a quantidade de cloro presente seja suficiente, as formas reduzidas desses metais serão oxidadas às suas formas de hidróxidos insolúveis.

Os nitritos também podem estar presentes na água, sendo rapidamente oxidados pelo cloro.

Uma grande quantidade de compostos orgânicos presentes na água pode exercer influência no consumo de cloro, dependendo da quantidade de cloro disponível e do tempo de reação.

O mecanismo de desinfecção com o uso de cloro não é ainda completamente conhecido. A comprovação experimental de que pequenas concentrações de ácido hipocloroso destroem 
bactérias levou Green \& Stumpf (apud Laubusch, 1971) à formulação da hipótese de que a morte da célula bacteriana era resultado da reação química do ácido hipocloroso com uma enzima, triosefosfato dihidrogenase, essencial na oxidação da glicose e, portanto, na atividade do metabolismo celular (funções respiratórias). Essas interações também ocorrem com outras enzimas. Entretanto, esta enzima, quando isolada, era oxidada por outros agentes que não o cloro, o que não ocorria com a enzima de células intatas. Esta observação indicou que a facilidade de penetração do desinfetante na célula é um fator importante. Em relação aos esporos, provavelmente sua inativação ocorre por métodos distintos daqueles das células vegetativas, conforme observações de que a sua sobrevivência não é dependente da capacidade do cloro de oxidar a glicose. A sobrevivência dos esporos é determinada por sua capacidade de formar células vegetativas e, mesmo após o contato com o cloro, é possível que os esporos continuem capazes de produzir a enzima, o que não acontece com as formas vegetativas, que perdem esta capacidade de regenerar a enzima.
A superioridade da eficiência de desinfecção do ácido hipocloroso em relação a outras formas de cloro é atualmente creditada não somente à sua forte capacidade de oxidação, mas também ao pequeno tamanho de sua molécula e sua neutralidade elétrica, que permitem uma rápida penetração nas células. A reduzida ação bactericida dos íons hiploclorito é relacionada à sua carga negativa, que provavelmente impede sua penetração na célula (Fair et al. apud Laubusch, 1971).

\section{FORMAÇÃO DE TRIHALOMETANOS}

A reação do cloro com alguns compostos orgânicos leva à formação de trihalometanos (THM). A água bruta contém ácidos fúlvicos e húmicos (fórmulas ainda não completamente conhecidas), resultantes da decomposição de folhas da vegetação (Opas, 1987). A maioria desses ácidos contém radicais cetona, que podem causar a formação de halofórmios após a reação com o cloro (Van Bremem, 1984).

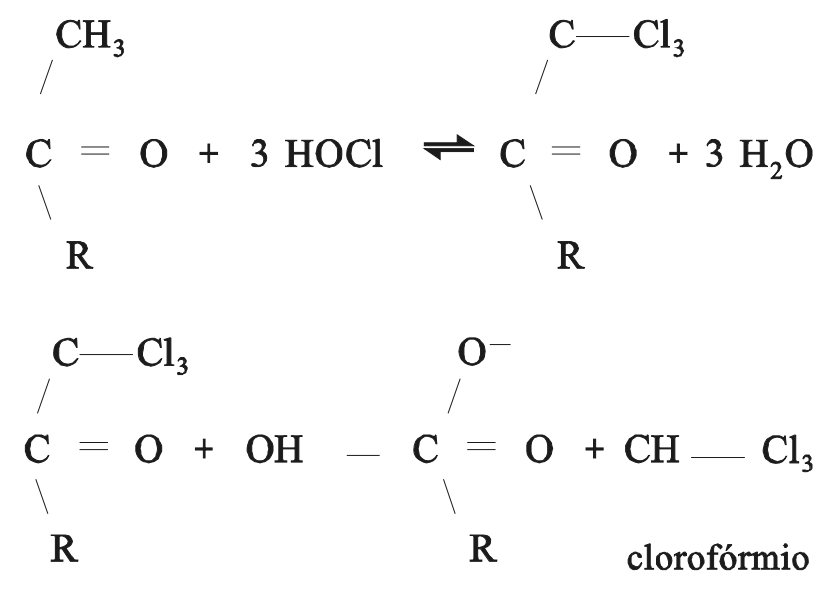

Os trihalometanos são, basicamente:

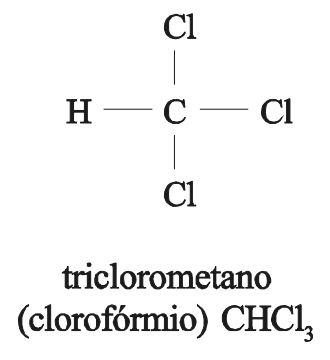<smiles>ClC(Cl)Br</smiles>
bromodiclorometano $\mathrm{CHBrCl}_{2}$


<smiles>ClC(Cl)C(Br)(Br)[Ge](Br)(Br)C(Br)Br</smiles>

dicloroiodometano<smiles>ClCI</smiles>

clorodiiodometano<smiles>BrCI</smiles>

\section{bromodiiodometano}

Entre os compostos relacionados, os que têm concentração mais significativa em água potável são os quatro primeiros: triclorometano, bromodiclorometano, dibromoclorometano e tribromometano (Santos, 1987). Portanto, quando se faz referência aos THM (trihalometanos), na realidade estão sendo mencionados os quatro compostos citados.

O THM mais facilmente detectável é o clorofórmio.

Os ácidos húmicos e fúlvicos são chamados "precursores" dos trihalometanos.<smiles>BrC(Br)Br</smiles>

tribromometano

$\mathrm{CHBr}_{3}$<smiles>ClC(Br)I</smiles>

bromocloroiodometano<smiles>BrC(Br)I</smiles>

dibromoiodometano<smiles>CI</smiles>

\section{triiodometano}

A reação de formação dos THM se inicia quando há o contato entre os reagentes (cloro e precursores) e pode continuar ocorrendo por muito tempo, enquanto houver reagente disponível (principalmente o cloro livre).

Segundo Perry (1983), o equilíbrio na cloração entre as reações de substituição envolvendo, inicialmente, a formação de ligações carbono-cloro, ou nitrogênio-cloro, e reações gerais de oxidação é importante na formação dos THM. Reações adicionais não têm muita importância, porque são, em geral, bem mais lentas. 
A reação do halofórmio envolve uma série de reações básicas catalíticas de substituição de um grupo a-carbonil, seguida, eventualmente, pela hidrólise para produzir o trihalometano. Para os compostos simples que contêm acetil, o patamar de determinação de baixa velocidade é a desagregação do próton, que é independente da concentração de halogênios, mas altamente dependente do $\mathrm{pH}$.

As variáveis que influenciam a reação de formação dos THM são (Khordagui \& Mancy, 1983; Santos, 1987; Van Bremer, 1984):

\section{Tempo}

Em relação ao tempo, a formação de trihalometanos em condições naturais não é instantânea. Em princípio, quanto maior o tempo de contato entre o cloro e os precursores, maior será a probabilidade de formação dos THM.

\section{Temperatura}

$\mathrm{O}$ aumento da temperatura significa um aumento na probabilidade de formação dos THM.

3. $\mathrm{pH}$

A formação dos THM aumenta com a elevação do $\mathrm{pH}$, pela sua ação catalítica sobre o halofórmio.

\section{Concentração de brometo e iodeto.}

Os brometos e iodetos, na presença de cloro aquoso, são oxidados a espécies capazes de participar da reação de substituição orgânica, resultando na formação de THM puro ou misturado (um ou mais de um dos compostos). O bromo tem vantagens sobre o cloro nas reações de substituição com os compostos orgânicos, mesmo que o cloro esteja presente em excesso quando comparado com o bromo inicial.

\section{Características e concentrações \\ dos precursores}

Quanto maior a concentração de ácidos húmicos e fúlvicos, maior será a formação de THM. As características da água e dos precursores presentes também irão influenciar a formação de THM.

\section{Concentração de cloro}

Quanto maior a dosagem de cloro, maior será a probabilidade de formação de THM. A forma sob a qual o cloro se apresenta também é importante; o cloro livre tem maior poder de formação de THM do que o cloro combinado.

\section{IMPORTÂNCIA DOS TRIHALOMETANOS}

A relação entre o uso de cloro nas estações de tratamento de água, suas reações com os compostos orgânicos presentes e a formação de compostos que o poderiam ter efeitos negativos sobre a saúde humana foi estudada pela primeira vez por R. H. Harris, na década de 70 (Santos, 1987). A partir de suas indicações pioneiras sobre a possibilidade de existir uma correlação entre águas de abastecimento e câncer, outros pesquisadores passaram a estudar o assunto, como Rook, na Holanda, e Bellar, Litchtemberg $\&$ Krones, nos Estados Unidos.

O aumento da preocupação com os níveis desses compostos presentes na água tem levado a amplas discussões sobre a legislação em inúmeros países (Perry, 1983).

A Agência de Proteção Ambiental dos Estados Unidos (USEPA), em um estudo no qual foram analisadas amostras de água provenientes de 113 estações de tratamento, detectou a presença de 27 compostos orgânicos com probabilidade de serem causadores de doenças (op. cit). Nessa relação de compostos, os quatro trihalometanos foram considerados muito importantes, porque surgiram com frequiência muito grande em todas as pesquisas realizadas nas águas de abastecimento cloradas. Como consequiência deste estudo, a EPA propôs, em 1978, o limite máximo permissível de $100 \mu \mathrm{g} / \mathrm{l}$ THM para águas de abastecimento. Embora não existissem provas cabais de que esses compostos pudessem ser nocivos à saúde, o limite foi proposto com objetivos preventivos. Em 1979, o critério adotado de $100 \mu \mathrm{g} / \mathrm{L}$ (média de concentração anual) foi regulamentado, apesar das evidências de carcinogenicidade do clorofórmio terem sido obtidas apenas em estudos com animais (Khordagui \& Mancy, 1983). Posteriormente, alguns estudos realizados no Canadá considerando a cloração de água bruta (Wigle apud Santos, 1989) indicaram uma associação entre a dosagem de cloro e o câncer de estômago, e entre a quantidade de carbono orgânico (COT, indicador de THM) e o câncer 
do intestino grosso em homens. Também houve associações positivas entre o clorofórmio na água tratada e o risco de morte por câncer de cólon (homens e mulheres), câncer de estômago, entre dosagem de cloro e câncer retal (homens e mulheres) e câncer de tórax. Para mulheres também houve associação entre dosagem de cloro ou água clorada sujeita a contaminação por substâncias orgânicas e câncer do cólon e cérebro.

O clorofórmio induz ao câncer de fígado, tiróide e rins em ratos e camundongos, mas associações significantes não foram observadas no homem.

Outros países seguiram os Estados Unidos em relação à legislação, sendo adotados os padrões de $350 \mu / 1$, no Canadá, $25 \mu / 1$, na Alemanha, 75 $\mu / 1$, na Holanda, e $10 \mu / 1$, na França (Perry, 1983). A controvérsia que cerca a formação dos THM é cientificamente complexa e as alterações que estão sendo introduzidas em legislação estão baseadas em dados incompletos.

Os níveis de THM refletem claramente as práticas adotadas no tratamento e na distribuição da água em países diferentes, além da qualidade das águas brutas (op. cit). Na Alemanha, por exemplo, onde são utilizadas águas que possuem níveis de carbono orgânico total reduzidos $(2 \mathrm{mg} / \mathrm{l})$ e a dosagem de cloro é limitada a menos de $1 \mathrm{mg} / \mathrm{l}$, os níveis de THM são bem mais baixos do que nos Estados Unidos, onde os processos de precloração levam a níveis mais altos de THM na água. No Reino Unido, os níveis consideravelmente elevados de THM são associados à precloração e à utilização de águas com alto teor de carbono orgânico total (COT).

No Brasil, a partir da promulgação da Portaria No 36, de 19/01/90, do Ministério da Saúde, foram estabelecidos novos padrões de potabilidade da água, os quais passaram a vigorar em 23/01/92. Conforme essa legislação, o teor máximo de trihalometanos em água potável foi fixado em $100 \mu \mathrm{g} / \mathrm{l}$.

A qualidade da água e sua origem, seja ela proveniente de planícies, planaltos ou do solo, é importante em relação à formação dos THM, já que este é um processo relacionado com a natureza do conteúdo orgânico da água. Os materiais húmicos e fúlvicos são considerados os precursores de THM de maior importância presentes em águas naturais (Van Bremem, 1984).

As variações sazonais nas concentrações de THM ocorrem em função das variações da temperatura da água, mas também tem relação com as alterações nas concentrações dos precursores. A concentração de algas também influencia a formação dos THM (Perry, 1983).

\section{DEFINIÇÕES DAS CONCENTRAÇÕES DE TRIHALOMETANOS}

Santos (1989) relacionou algumas definições usuais de concentração de trihalometanos: THM totais, THM instantâneo, THM final, potencial de formação de THM e precursor total.

THM Totais (THMT) - é a soma das concentrações dos quatro THM encontrados com maior frequiência, expressa em $\mu \mathrm{g} / \mathrm{l}$. As concentrações desses quatro compostos são medidas conjuntamente, uma vez que eles são formados por reações similares, medidos por técnicas similares (cromatografia), podem ter os mesmos efeitos tóxicos e são passíveis de controle por técnicas similares de tratamento.

THM Instantâneo (THMinst) - é a concentração de HM na água no momento da amostragem. Deve ser expressa em termos de tipo individual ou a soma do total de THM (TTHM). É o parâmetro medido no sistema de distribuição para fornecer os dados necessários para que seja verificado o MCL (nível de contaminante máximo).

THM Final $\left(\right.$ THM $\left._{\mathrm{f}}\right)$ - é a concentração de THM que ocorre na determinação da medida deste parâmetro. Para medir a concentração de THM, as condições de reação cloro-precursor são selecionadas de acordo com o tratamento que é dado à água em questão. Em geral, uma amostra de água é clorada sob estas condições e o clorofórmio e outros tipos de $\mathrm{THM}_{\mathrm{f}}$ são medidos após um período de tempo específico. $\mathrm{O} \mathrm{THM}_{\mathrm{f}}$ é importante também para se avaliar os riscos do consumidor, assim como o THMinst. Devido ao fato deste parâmetro ser uma medida do somatório das quantidades de THM já presentes (instantâneos), e estes serem formados durante o tempo de reação, um terceiro parâmetro útil para a avaliação da permanên- 
cia ou não de processos unitários para remoção dos precursores deve ser definido.

Potencial de Formação de Trihalometanos (THMFP) - é a diferença aritmética entre o THM final e o THM instantâneo, e representa a concentração de precursor que não reagiu e que está presente na água na hora da amostragem original. O THMFP é uma medida da quantidade do material precursor total que está na água em um dado ponto do sistema de tratamento, sendo de grande interesse para o operador da estação. Este parâmetro, quando determinado nas amostras de água do afluente e do efluente da estação de tratamento, pode ser usado para verificar a eficiência do processo adotado para a remoção dos precursores.

Precursor Total - é a concentração de todo material precursor de THM presente na água que pode reagir com os halogênios sob condições que maximizem a produção de THM. É importante a distinção entre o THMFP e o precursor total. Não existe nenhum processo padronizado para esta medida (precursor total). Entretanto, pesquisas devem ser realizadas para que seja estabelecida a condição ótima em que possa ser conseguida a reação completa de todos os precursores para se produzir as concentrações de THM máximo teóricas. Como as condições de cloração para as medidas de $\mathrm{THM}_{\mathrm{f}}$ são de alguma forma menores que as condições ótimas para a formação de THM, o $\mathrm{THM}_{\mathrm{f}}$ obtido em qualquer teste será menor que o teórico. Portanto, o valor obtido para o THMFP nessas condições será menor que o precursor total teórico. Embora os valores obtidos de THMFP não sejam do "precursor total", o THMFP é um índice de concentração de materiais da maior importância em relação à formação de THM para uma estação de tratamento de água e para o sistema de distribuição. Para se comparar os resultados do tratamento de uma estação para outra, ou dentro de uma mesma estação onde as condições de reação sejam causadas por diferentes condições de tratamento, é aconselhável que a seleção seja feita com base num conjunto único de testes padrões. Esta comparação, entretanto, não é tão eficiente quanto a avaliação direta de remoção de precursores na estação, onde é avaliada a sua própria capacidade para encontrar o limite (MCL) para THM.

\section{CONTROLE DOS TRIHALOMETANOS}

As recomendações para o controle dos THM variam de pequenas alterações nos tipos de tratamento existentes até mudanças de alto custo nos sistemas de tratamento. O importante é que qualquer mudança proposta para um sistema de tratamento não acarrete uma deterioração na qualidade da água pronta para o consumo.

Os métodos para o controle da formação dos THM podem ser classificados em redução da concentração dos precursores e uso de processos alternativos para a desinfecção. Outra alternativa de controle é a retirada dos THM já formados (Bazzoli, 1993; Khordagui \& Mancy, 1983).

\section{Redução da Concentração de Precursores}

A diminuição da concentração dos precursores pode ser conseguida através da aplicação de diversas técnicas de acordo com Perry (1983) e Santos (1989):

\section{Clarificação}

A coagulação é considerada uma técnica de tratamento para a redução de turbidez, mas também apresenta um grande significado na remoção de orgânicos. Alguns compostos orgânicos são, provavelmente, absorvidos junto com as partículas em suspensão (turbidez), entre os quais os ácidos húmicos e fúlvicos. Esses compostos são parcialmente removidos nos processos de coagulação/precipitação numa estação de tratamento de água. Os ácidos húmicos são responsáveis, em parte, pela coloração de algumas águas, podendo ser removidos pela aplicação de coagulantes à água, como os sais de ferro e alumínio. A remoção de orgânicos pela coagulação é melhor realizada sob condições levemente ácidas ( $\mathrm{pH} 4$ a 6).

\section{Controle de precursores no manancial}

A realização de determinações periódicas da concentração de precursores de THM em água bruta pode revelar medidas de controle que poderiam ser tomadas para minimizar essas concentrações. Entre tais medidas deveriam ser 
incluídos o controle de algas, a prevenção do avanço de água salina (presença de compostos bromados) e a seleção de mananciais alternativos.

\section{Aeração}

A aeração já foi aplicada como uma técnica alternativa de remoção dos precursores de THM. Entretanto esta técnica não foi eficiente, o que é explicado pelo conhecimento atual de que as moléculas dos ácidos fúlvicos e húmicos têm peso molecular elevado.

\section{Oxidação}

O uso de agentes oxidantes capazes de oxidar os precursores de THM tem como objetivo a diminuição do potencial de formação de trihalometanos pela ação de produtos químicos (alterando os precursores) e a completa oxidação química dos precursores (até a forma de dióxido de carbono), a fim de se eliminar o problema potencial da presença depois do tratamento de subprodutos da oxidação, os quais podem ser até mais perigosos do que os THM.

Os oxidante que podem ser usados são os seguintes: ozona, dióxido de cloro, permanganato de potássio, radiação ultravioleta e peróxido de hidrogênio. As dosagens necessárias desses oxidantes para reduzir o potencial de formação de THM são elevadas e o tempo de contato é maior que o normalmente usado na desinfecção.

A alternativa de oxidação dos precursores até hoje foi realizada somente a nível de estudos, não tendo sido implementada como rotina em sistemas de tratamento de água. Existe a possibilidade de que a utilização desta técnica implique a geração de subprodutos indesejáveis. As reações de oxidação dos precursores são bastante complexas e os subprodutos obtidos podem variar com as condições da reação de remoção do potencial de formação de trihalometanos.

Águas que apresentam concentração elevada de bromo produzem teores elevados de trihalometanos. Tais águas podem ser tratadas com ozônio para retardar ou prevenir a formação de THM contendo bromo, o que resulta numa diminuição da concentração total de trihalometanos.

\section{Adsorção em carvão ativado em pó}

Os precursores de THM são uma mistura de muitos produtos químicos, e esta mistura varia conforme o corpo hídrico em questão. $\mathrm{O}$ tratamento por adsorção dessas substâncias é mais difícil que o tratamento de produtos identificados individualmente.

Os materiais húmicos aquáticos são os mais relevantes dentre os precursores dos THM e não são uma única substância. As características desses compostos são influenciadas por numerosos fatores que alteram sua capacidade de adsorção, tais como distribuição do peso molecular, pH, íons inorgânicos presentes, fonte dos precursores e frações relativas dos ácidos húmicos e fúlvicos. Essas variáveis influenciam as características físico-químicas da solução e a própria superfície do carvão ativado (o que afeta a adsorção, mesmo de substâncias puras).

\section{Adsorção em carvão ativado granular}

O carvão ativado granular é eficiente na remoção da maioria dos precursores dos THM. Entretanto, ele tem a desvantagem de necessitar que o carvão ativado granular seja substituído com freqüencia, para manter a eficiência de remoção do material orgânico. A freqüência de regeneração do meio filtrante depende da carga orgânica sobre os filtros e do tipo de precursores a serem removidos.

\section{Resinas trocadoras de íons}

Algumas resinas trocadoras de ânions já foram testadas na remoção dos precursores de THM, apresentando resultado satisfatório.

\section{Processos Alternativos de Desinfecção}

Os processos alternativos de desinfecção da água, que evitam a formação de THM, são aqueles que não utilizam cloro livre, tais como: cloraminas (cloro combinado), dióxido de cloro, ozonização, permanganato de potássio, peróxido de hidrogênio, cloreto de bromo, bromo, iôdo, íon ferrato, alto $\mathrm{pH}$ e radiação utravioleta (Laubusch, 1971; Santos, 1987). Destes, os 
mais utilizados são as cloraminas, o dióxido de cloro e a ozona.

Embora o uso desses compostos na desinfecção ofereça a vantagem de não contribuir para a formação dos THM, outros subprodutos podem ser produzidos, conforme o teor de matéria orgânica presente na água (Santos, 1989). Esses subprodutos apresentam a mesma dificuldade de remoção que os THM, sendo que seus efeitos sobre a saúde não foram ainda completamente avaliados. Além disso, cada um dos desinfetantes apresenta outras desvantagens: a ozona não produz residual para o sistema de distribuição; a cloramina é um desinfetante mais fraco que o cloro livre, podendo ter alguma toxicidade; e o dióxido de cloro produz cloritos e cloratos como subprodutos, bem como outras espécies aniônicas, cujo efeito à saúde é desconhecido.

\section{Remoção dos THM}

A alternativa de remoção dos THM já formados significaria a construção de mais uma unidade numa estação de tratamento de água, existindo, entretanto, a possibilidade de aproveitamento das unidades já existentes.

O carbono granular ativado é considerado, segundo Perry (1983), o método mais eficiente na redução da concentração de THM, sendo recomendado seu uso pela EPA (também serve para remover outros contaminantes ainda não determinados). Entretanto, a necessidade de regenerar o meio filtrante com freqüência, de modo a garantir a eficiência da remoção de material orgânico, é uma desvantagem do método.

\section{CONCLUSÕES}

Os levantamentos epidemiológicos relacionando a concentração dos THM com a morbidade e a mortalidade por câncer não são estatisticamente conclusivos, mas evidenciam associações positivas em alguns casos de carcinomas. A substituição do cloro por outro desinfetante no tratamento da água pode trazer mais riscos do que benefícios. A diminuição da incidência de doenças transmissíveis pela água somente foi alcançada com a difusão do emprego da técnica da cloração.
O monitoramento da concentração de THM em águas (brutas e distrbuídas) e a avaliação de sua formação durante o processo de tratamento devem preceder qualquer decisão que acarrete alguma mudança em um sistema de tratamento de água.

A legislação brasileira de padrões de potabilidade da água recentemente adotou um novo valor para a concentração dos THM em águas (Portaria N ${ }^{\circ} 36$, de 19/01/90). Contudo, na maioria dos estados brasileiros não é realizado um monitoramento da concentração do parâmetro. Além do monitoramento na própria estação, é necessário que esta avaliação também seja realizada nas pontas de rede (final da linha de distribuição). Como a reação de formação dos THM é lenta, ela pode ser iniciada no processo de cloração e continuar acontecendo até a água ser utilizada pelo consumidor.

A ocorrência da cólera no Brasil, a partir de 1991, provavelmente resultou num aumento nas dosagens de cloro usadas em muitos sistemas. A avaliação dos riscos de uma elevação da concentração de cloro (possibilidade de formação dos THM) e a necessidade de existir uma barreira sanitária para se evitar a propagação da doença constituem uma questão delicada, que deve ser estudada para cada manancial usado como fonte de abastecimento, já que as características da água desempenham um papel importante na formação dos THM.

Finalmente, deve ser enfatizado que os THM não são o único risco existente em relação à cloração das águas. Em função dos compostos orgânicos presentes na água bruta, outros subprodutos da cloração, mais perigosos que os THM, podem ser formados. Portanto, além do seu próprio significado, os THM servem como indicadores da existência de outros compostos, possivelmente ainda mais perigosos que eles mesmos. A eliminação de todos esses compostos na água consumida, sem que seja perdida a sua qualidade sanitária, é um problema complexo e de difícil solução. 


\section{RESUMO}

MEYER, S. T. O Uso de Cloro na Desinfecção de Águas, a Formação de Trihalometanos e os Riscos Potenciais à Saúde Pública. Cad. Saúde Públ., Rio de Janeiro, 10 (1): 99-110, jan/mar, 1994.

Antes do desenvolvimento da teoria dos microorganismos como causadores de doenças (1880), acreditava-se que estas eram transmitidas através de odores. A desinfecção, tanto da água de abastecimento como dos esgotos, surgiu como uma tentativa da eliminação desses odores. Existem muitos agentes desinfetantes, mas, em geral, o cloro é o principal produto utilizado na desinfecção de águas de abastecimento. A presença de compostos orgânicos em águas que sofrem o processo de cloração resulta na formação dos trihalometanos, compostos formados por um átomo de carbono, um de hidrogênio e três de halogênio (cloro, bromo, iôdo). Os trihalometanos são considerados compostos carcinogênicos e sua presença na água deve ser evitada. Levantamentos epidemiológicos relacionando a concentração dos trihalometanos com a morbidade e a mortalidade por câncer evidenciaram associações positivas em alguns casos de carcinomas. Entretanto, a substituição do cloro por outro desinfetante no tratamento de água pode trazer mais riscos do que benefícios, considerando-se que a diminuição da incidência de doenças transmissíveis pela água somente foi alcançada com a difusão do emprego da técnica de cloração.

Palavras-Chave: Tratamento da Água; Cloro; Trihalometanos

\section{REFERÊNCIAS BIBLIOGRÁFICAS}

BAZZOLI, N., 1993. O Uso da Desinfecção no Combate à Cólera. Apostila da Fundação Nacional de Saúde - Coordenação Regional de Minas Gerais. Recife: FNS/Opas. (Mimeo.)

CUBILlOS, A., 1981. Calidad y Control de La polucion del Agua. Mérida: CIDIAT/Centro Interamericano de Desarollo Integral de Aguas y Tierras. (Mimeo.) (Série Ambiente y Recursos Naturales Renovables, AR 14).

DEGRÉMONT, 1979. Water Treatment Handbook. New York: John Wiley \& Sons.

FAIR, G. M.; GEYER, J. C. \& OKUM, D. A., 1954. Water and Wastewater Engineering. New York: John Wiley \& Sons.

GREEN, D. E. \& STUMPF, P. K., 1946. A note on the enzimatic method of estimating chlorine. Fournal of American Waterworks Association, 38: 1306.

KHORDAGUI, H. K. \& MANCY, H. K., 1983. Formation of Trihalomethanes During Disinfection of Drinking Water. Water Quality Bulletin, 8: 37-43.

LAUBUSCH, E. J., 1971. Chlorination and other disinfection processes. In: Water Quality and Treatment: A Handbook of Public Water Supplies (American Water Works Assocciation), pp. 158-224, New York: McGraw-Hill Book Company.

OPAS (Organización Panamericana de la Salud), 1987. Guias para la Calidad del Agua Potable. Volumes I, II e III. Genebra: Opas.

PERRY, R., 1983. Materiais Orgânicos Importantes no Ciclo da Água - Escoamento de Resíduos Industriais. I Seminário Anglo-Brasileiro de Controle Ambiental. São Paulo: British Council. (Mimeo.)

ROSSIN, A. C., 1987. Desinfecção. In: Técnica de Abastecimento e Tratamento de Água (Tratamento de Água), Vol. 2, São Paulo: CETESB/ASCETESB.

SANTOS, C. L., 1987. Trihalometanos Resumo Atual. Engenharia Santiária, 26: 190-194. , 1989. O Controle de Trihalometanos (THM) nas Águas de Abastecimento Público. Tese de Mestrado, São Paulo: Faculdade de Saúde Pública, Universidade de São Paulo.

VAN BREMEM, J., 1984. Water Quality. International Course in Sanitary Engineering. Delft: IHE/International Institute for Infrastructural, Hydraulic and Environmental Engineering. (Mimeo.) 